\title{
MORFOFISIOLOGIA OVARIANA DAS CADELAS
}

\author{
Ana Paula Zoppei ${ }^{1}$, Adalgiza Pinto Neto $^{2}$, William de Oliveira ${ }^{3}$, Antonio Campanha \\ Martinez ${ }^{4}$ \\ ${ }^{1}$ Graduanda. Curso de Medicina Veterinária. Universidade Federal da Fronteira Sul. \\ Campus Realeza. Realeza-PR. \\ ${ }^{2}$ Docente. Curso de Medicina Veterinária. Universidade Federal da Fronteira Sul. \\ Campus Realeza. Realeza-PR. \\ ${ }^{3}$ Mestrando em Saúde Animal e Desenvolvimento Sustentável na Fronteira Sul. \\ Universidade Federal da Fronteira Sul. Campus Realeza. Realeza-PR. \\ ${ }^{4}$ Docente. Programa de Pós-Graduação em Saúde e Produção Animal Sustentável. \\ Universidade Estadual de Maringá. Umuarama-PR.
}

Email: adalgiza.neto@uffs.edu.br; adalgiza.uffs@gmail.com

\section{Recebido em: 06/04/2019 - Aprovado em: 10/06/2019 - Publicado em: 30/06/2019 DOI: 10.18677/EnciBio_2019A92}

\begin{abstract}
RESUMO
As cadelas são monoestrais, poliovulatórias e não sazonais, cujo ciclo estral é regulado por mecanismos de feedback entre neurônios e células secretoras do eixo reprodutivo (Hipotálamo-Hipófise-Ovários). Seus ovários são formandos pela migração das células germinativas até a crista gonadal, povoando os cordões sexuais, que contribuem como células foliculares (Células da Granulosa), que envolvem o oócito, diferenciando-se em Células do Cumulus. Adicionalmente, há as Células da Teca que se desenvolvem em camadas internas e externas. Os folículos permanecem na camada cortical, enquanto que na medular há tecido conjuntivo, nervos e vasos sanguíneos. No pico de Hormônio Luteinizante ocorre a liberação do oócito (ovulação), enquanto que a folículogenese é estimulada pelo Hormônio Folículo Estimulante. Diferentemente de outros mamíferos, a oogênese das cadelas ocorre até dois meses após seu nascimento, pois há células em proliferação na região cortical do ovário, observando um aumento importante dos grânulos lipídicos, resultando em uma aparência escura ao oócito, e apresenta ainda folículos polioocitários, que diminuem durante a senilidade. $\mathrm{O}$ aumento das concentrações séricas de Estradiol folicular culmina em alterações de comportamento das cadelas no estro, cujas fases do ciclo estral poderiam ser detectadas pela citologia vaginal. Concluí-se que o conhecimento da anátomo fisiologia dos órgãos reprodutivos das cadelas, bem como a interação endócrina para o controle do ciclo estral, é importante para o manejo reprodutivo eficiente, para o controle da superpopulação canina, para o uso correto de biotécnicas e/ou controle de enfermidades reprodutivas.
\end{abstract}

PALAVRAS-CHAVE: Ciclo estral; Ovário; Reprodução canina. 


\title{
OVARIAN MORPHOPHYSIOLOGY IN BITCHES. LITERATURE REVIEW
}

\begin{abstract}
Bitches are monoestral, polyovulatory, and nonseasonal animals, whose estrous cycle is regulated by feedback mechanisms between neurons and secretory cells of the reproductive axis (hypothalamus-hypophysis-ovaries). Their ovaries are formed by migration of germ cells to the gonadal ridge, populating the sex cords, which contribute as follicular cells (granulosa cells), which involve the oocyte, differentiating in cumulus cells. In addition, theca cells develop in internal and external layers. The follicles remain in the cortical layer, whereas connective tissue, nerves, and blood vessels are in the medullar layer. The release of the oocyte (ovulation) occurs at the peak of the luteinizing hormone, whereas the folliculogenesis is stimulated by the follicle-stimulating hormone. Different from other mammals, oogenesis in bitches occurs up to two months after birth, since there are proliferating cells in the cortical region of the ovary, significantly increasing lipid granules, resulting in a dark oocyte. Polyoocyte follicles are also found, which reduce during senescence. The increase in serum levels of follicular estradiol changes the behavior of bitches in the estrous cycle, whose phases could be detected by vaginal cytology. Information about anatomical physiology of reproductive organs of bitches, and endocrine interaction to control the estrous cycle is important for an efficient breeding management, control of canine overpopulation, and correct use of biotechniques and control of reproductive diseases.
\end{abstract}

KEYWORDS: Canine reproduction; Estrous cycle; Ovary

\section{INTRODUÇÃO}

Os cães (Canis familiaris) foram originados a partir da espécie do lobo cinzento (Canis lupus) há cerca de cem mil anos, quando em sua região Crescente Fértil, que atualmente inclui Iraque, Síria, Líbia e Jordânia, a agricultura e pecuária começavam a se intensificar, facilitando o processo de sedentarismo do ser humano e domesticação desses animais (SILVA, 2011).

Com o passar dos anos, a presença do cão nos lares tornou-se intensa a ponto de substituir a presença de filhos por espécimes desses animais, com estimativa de aproximadamente um bilhão de cachorros no planeta (MAZON; MOURA, 2014). Evangelista et al. (2016) relataram que técnicas reprodutivas foram desenvolvidas então, em prol da preservação da espécie, a fim de aumentar o número desses animais na sociedade, e em modelos experimentais para o avanço dessas biotécnicas em outras espécies. A aplicação dessas técnicas só é possível a partir do conhecimento anatômico e fisiológico das fêmeas caninas.

A cadela apresenta o sistema reprodutor composto pela vulva, vagina, cérvix, útero, tubas uterinas e ovários (SAPIN et al., 2017). Anatomicamente, a vulva é caracterizada como o órgão reprodutor feminino externo, formado pela presença de dois lábios que se encontram em uma comissura dorsal e outra ventral; a vagina corresponde a parte cranial do sistema reprodutor da fêmea, prolongando-se do óstio uterino externo até o óstio externo da uretra, sendo um órgão relativamente longo, com paredes finas formando uma cavidade virtual; a cérvix é um órgão de proteção, que atua como um esfíncter entre o meio externo e interno; o útero é um órgão oco, composto por uma camada mucosa (endométrio), uma camada muscular (miométrio) e uma camada serosa (perimétrio), e possui a função de permitir a implantação do embrião, manter a gestação e expulsar o feto no 
momento do parto; as tubas uterinas captam o oócito proveniente dos ovários pelas fímbrias (porção final), sua porção medial é a ampola, onde ocorre a fertilização, e por mecanismo de contra corrente, transporta os espermatozoides vindos do útero pelo infundíbulo; os ovários são responsáveis pela produção dos oócitos, que é o gameta feminino, e regulação do ciclo estral nas fêmeas (KÖNIG; LIEBICH, 2011).

Previato et al. (2005) relataram que a atividade reprodutiva das fêmeas canis é regulada por ciclos estrais, iniciada após a puberdade, onde ocorre liberação de gametas e modificação comportamental, marcando a funcionalidade do sistema reprodutor feminino, regulado pelo eixo reprodutivo. A interação do Hipotálamo, Hipófise e Ovários, por meio de mecanismos de feedback entre neurônios e células secretoras, e a capacidade dos receptores nas células-alvo em detectar essas ações, regulam o ciclo estral (GOSSLER, 2015).

Costa et al. (2009) definiram a puberdade como ajuste do crescimento da atividade gonadotrófica e habilidade das gônadas em realizar esteroidogênese e gametogênese. Thompson (2006) relata que esse período é definido quando a fêmea apresenta primeiro estro com presença de ovulação e formação de Corpo Lúteo. Particularmente, quando comparada a outras espécies, as cadelas apresentam características específicas em seu ciclo estral. São animais moniciclícas com a fase luteínica se assemelhando a animais gestantes e não gestante, com um anestro prolongado, relacionando o ciclo estral com os fenômenos de puberdade, maturidade sexual e senescência (OLIVEIRA, 2003).

O intervalo dos ciclos estrais é definido desde o início da receptividade da fêmea em relação ao macho até seu período seguinte, ou simplesmente o período entre as sucessivas ovulações, provocando alterações comportamentais, além de metabólica no organismo como um todo (COSTA et al., 2009).

Diferentemente de outros mamíferos, a oôgenese das cadelas, período que compreende a produção oocitária pelas oôgonias ou células germinativas primordias, ocorre até dois meses após o nascimento, pois há células em proliferação em região cortical do ovário. Durante todo o processo de oogênese canina, ocorre aumento dos grânulos lipídicos, resultando em uma aparência escura ao oócito canino, que não ocorre em outros mamíferos (DERUSSI; LOPES, 2009).

Foi observada que na cadela, a foliculogênese possui alta incidência de folículos polioocitários, com maior concentração em cadelas jovens, diminuindo durante sua senilidade (RÔLO, 2012). Bysted et al. (2001) e Reynaud et al. (2005) relataram que folículos multioocitários também podem ovular, podendo liberar oócitos diferentes morfologicamente entre si, variando em número de duas a dezesste células germinativas (CARDOSO, 2017), com causas ainda desconhecidas. Um dos motivos pode estar relacionado a alta densidade de folículos pré ovulatórios no cortex do animal jovem (DERUSSI; LOPES, 2009).

A origem desses folículos multioocitários é desconhecida, mas pode estar associada a falhas na degradação de células germinativas, ou estádios iniciais da folículogênese, e que a taxa de desenvolvimento é mais rápida que a diferenciação das células somáticas circundantes (PAYAN-CARREIRA; PIRES, 2007). Lunardon et al. (2015) relatam que a porcentagem desses folículos multioocitários reduzem a com o aumentar da idade do animal.

Nesse contexto, objetiva-se com esse estudo revisar a literatura sobre a morfofisiologia ovariana das cadelas, englobando aspectos relevantes da anátomo fisiologia dos ovários, das fases do ciclo estral, da estimativa do ciclo estral por 
citologia vaginal e da fisiologia da ovulação, sem, contudo, esgotar a literatura sobre o assunto.

\section{ANATOMIA E ESTRUTURA HISTOLÓGICA DOS OVÁRIOS DAS CADELAS}

As gônadas indiferenciadas formam-se a partir de células germinativas pela ausência ou presença do fator de diferenciação testicular (TDF), sendo no caso da origem dos ovários, ausência deste fator (SAPIN et al., 2017). Sapin et al. (2017) relataram que a diferenciação em fenótipo feminino ocorre a partir do desenvolvimento dos ductos paramesonéfricos, que possuem a capacidade de originar tubas uterinas, útero e vagina.

O sistema reprodutor feminino tem a função primordial de produção de gameta, o oócito, manutenção do embrião durante a gestação e produção de hormônios que influenciam no ciclo estral (JUNQUEIRA; CARNEIRO, 2013). Segundo König e Liebich (2011), os ovários se originam do primórdio gonadal e localizam-se na região dorsal do abdomem caudal aos rins, apresentando formato de elipse e riniforme (BINSFELD et al., 2014), com dimensões que variam de 1 a 1,5 centímentros de diâmetro, com superfície repleta de folículos e corpos lúteos. São fixados à parede lateral pélvica, pelos ligamentos largo direito e esquerdo e os ligamentos suspensores do ovário na $13^{\circ}$ costela; a bolsa ovárica é envolvida por tecido adiposo formada pelo mesovário e mesossalpinge (BARROS, 2010).

A formação do ovário decorre da migração de células germinativas primordiais que provém do saco vitelínico em direção a crista gonadal, povoando os cordões sexuais, contribuindo como células foliculares, posteriormente Células da Granulosa, que envolverão o oócito. Ao redor do oócito, as Células da Granulosa são denominadas Células do Cumulus. A crista gonadal forma as Células da Teca, que circundam externamente a parede do folículo. Assim, o folículo compreende o oócito, circundado pelas Células do Cumulus, as Células da Granulosa e as Células da Teca (DAVIDSON; STABENFELDT, 2008)

A superfície ovariana apresenta epitélio cúbico simples, denominado epitélio germinativo. Logo abaixo desse epitélio há uma camada de tecido conjuntivo denso ou túnica albugínea, seguido da região cortical, onde encontram-se os folículos em diferentes estádios de desenvolvimento e tamanho. Os folículos estão localizados no estroma, que é a região de tecido conjuntivo predominante na cortical do ovário, contendo fibroblastos que se arranjam em redemoinhos e respodem a hormônios. $A$ região medular é composta por tecido frouxo, leito vascular e nervos (JUNQUEIRA; CARNEIRO, 2013).

Os folículos presentes na região cortical ovariana são classificados como primordiais, primários, secundários, terciários (antrais) e pré-ovulatórios (ou de Graaf) (JUNQUEIRA; CARNEIRO, 2013). Os folículos primordiais são formados durante a vida fetal, onde as células pré-granulosa, recrutadas das células mesoteliais do epitélio ovariano, circundam os oócitos, formando os folículos primordiais. Os oócitos são a diferenciação das Gélulas da Granulosa que colonizam o ovário durante sua formação. As células da pré-granulosa, após circundarem os oócitos, entram em um estado de quiescência e sua proliferação volta ocorrer quando o folículo primordial retoma seu crescimento (JUNQUEIRA; CARNEIRO, 2013).

Quando as Células da Granulosa alteram o formato de suas células de achatadas para cúbicas ao redor do oócito, o folículo é classificado como primordial. No entanto, quando o oócito é circundado somente por células 
cúbicas, o folículo é classificado como primário (DERUSSI; LOPES, 2009). As Células da Granulosa do folículo primário se multiplicam, originando os folículos secundários, que possuem várias camadas celulares ao redor do oócito, além de duas a três camadas celulares externas, percursoras das Células da Teca, recrutadas do estroma ovariano, separadas das Células da Granulosa por uma membrana basal, sendo estas essenciais para o desenvolvimento normal do folículo (SHRESTHA et al., 2015). A partir daí, tornam-se folículos terciários ou antrais (JUNQUEIRA; CARNEIRO, 2013).

No início do crescimento folicular, nos folículos secundários, as proteínas que formam a zona pelúcida, são sintetizadas pelo oócito, formando uma matriz extracelular glicoproteica entre o oócito e as Células do Cumulus, subdivida em três tipos: tipo 1 (ZP1), tipo 2 (ZP2) e tipo 3 (ZP-3) (DERUSSI; LOPES, 2009).

O Fator de Crescimento Semelhante a Insulina (IGF) interage com o eixo reprodutivo, regulando o crescimento folicular, as atividades luteais, interagindo com as gonadotrofinas provenientes da Hipófise, diferenciando as Células da Teca, bem como as Células da Granulosa, no envolvimento da esteroidogênese (ALMEIDA et al., 2015).

Davidson e Stabenfeldt (2008) relataram que há uma estrutura denominada Complexo Cumulus Oophorus, que contém o oócito em amadurecimento em uma extremidade da cavidade folicular, intimamente em contato com a zona pelúcida, envolvida por camadas de Células da Granulosa, que nesse local é denominada Coroa Radiada (KÖNIG; LIEBICH, 2011).

Bezerra et al. (1998) denominaram como folículos terciários, ou antrais, aqueles que apresentam uma cavidade (antro) preenchida por fluido folicular entre as camadas de Células da Granulosa, que aumenta progressivamente simultaneamente ao crescimento do oócito e a multiplicação das células da Granulosa e da Teca, até se tornar um folículo pré-ovulatório.

No folículo pré-ovulatório ou folículo de Graaf (KÖNIG; LIEBICH, 2011), o oócito é circundado por Células da Granulosa especializadas denominadas Células do Cumulus, conectadas e banhadas pelo fluido folicular. Estas células entram em um estádio de quiescência, devido a ação do Hormônio Luteinizante (LH), e a ovulação do oócito ocorre no pico de ação desse hormônio. Na maioria das espécies, a formação dos folículos pré ovulatórios ocorre na puberdade (LUCY et al., 1992).

Junqueira e Carneiro (2004) relataram que a ovulação ocorre quando há ruptura da parede do folículo maduro, com subsequente liberação do oócito, que será captado pelas fimbrias das tubas uterinas. Davidson e Stabenfeldt (2008) relataram que a proliferação dos oócitos ocorre por divisão mitótica durante o desenvolvimento fetal na maioria dos mamíferos, iniciando o processo de redução a células haplóides após o nascimento, por meio de meiose, sendo esse processo interrompido na fase de diplóteno, pertencente ao estádio I da meiose, por meio do fator inibidor da meiose, produzido pela rete ovarii.

O folículo ovulado sofre uma série de alterações morfológicas e funcionais, que originam o Corpo Lúteo, que é formado após a ruptura da parede folicular, que leva a hemorragia decorrente da ruptura dos vasos das Células da Teca, com preenchimento da cavidade folicular por sangue, consequente formação de coágulo e reorganização das Células da Granulosa e Teca, em células luteais (KÖNIG; LIEBICH, 2011). Nas cadelas, esse evento ocorre dentro de 12 a 96 horas após as ovulações (RIBEIRO, 2018) 
Junqueira e Carneiro (2004) relataram que após o sangramento decorrente da ovulação, um coágulo migra na cavidade antral e é invadido por tecido conjuntivo, que povoa a parte central do corpo lúteo. As Células da Granulosa aumentam de tamanho, e compreendem aproximadamente $80 \%$ do parênquima do corpo lúteo, e passam a ser denominadas Grandes Células Luteais, enquanto que as Células da Teca passam a ser denominadas Pequenas Células Luteais, e juntos passam a secretar Progesterona. Adicionalmente, os vasos sanguíneos expandem-se das Células da Teca para o interior dessa estrutura, formando uma extensa rede vascular.

Se não ocorrer fertilização, as células que formaram o corpo lúteo degenerarse-ão por apoptose, com decrescente secreção de Progesterona, os baixos níveis séricos de estradiol estimulam a secreção do Hormônio Folículo Estimulante (FSH), promovendo o crescimento folicular e iniciando um novo ciclo nas fêmeas. Os restos do corpo lúteo são fagocitados por macrófagos, e os fibroblastos formam uma cicatriz de tecido conjuntivo denso denominado Corpo Albicans (JUNQUEIRA; CARNEIRO, 2013). A regressão do corpo lúteo é dada pela liberação de prostaglandina $\left(\mathrm{PGF}_{2}\right)$ das glândulas endometriais (KÖNIG; LIEBICH, 2011).

Caso haja fertilização, o corpo lúteo permanece ativo, com ampla produção e liberação de Progesterona, que permanece durante todo o período de gestação (KÖNIG; LIEBICH, 2011). A progesterona também é responsável por promover resistência a Insulina, hormônio capaz de transportar a glicose a células e tecidos, reduzindo a sua ligação em receptores celulares (SCHNEIDER, 2017).

A Figura 1 ilustra uma representação esquemática da estrutura anatômica ovariana, contendo estruturas típicas de um ovário em uma fêmea cíclica.

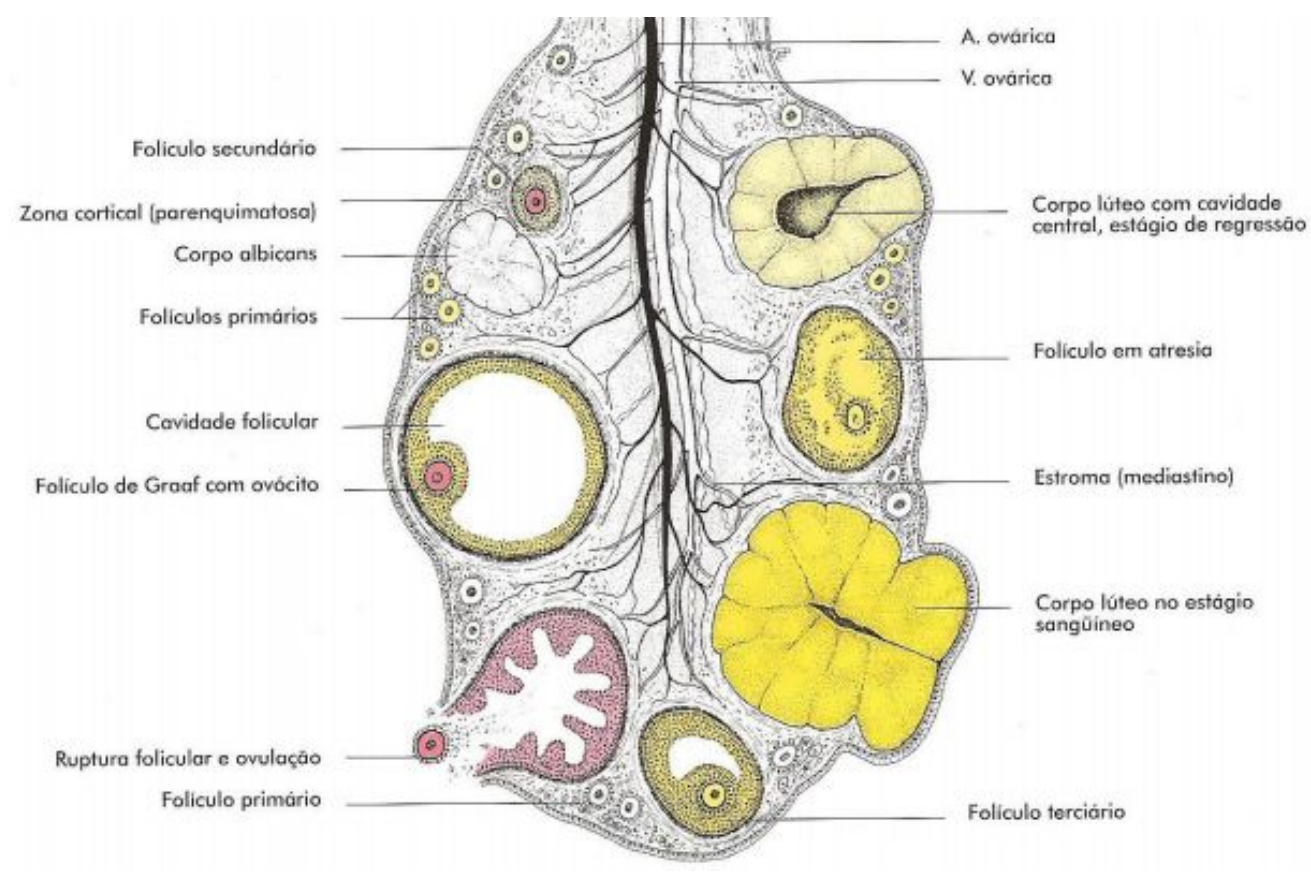

FIGURA 1: Estrutura ovariana de uma fêmea cíclica. Fonte: KONIG e LIEBICH (2004) 


\section{Proestro}

\section{FASES DO CICLO ESTRAL}

O Proestro é a fase do ciclo estral determinada pelo início do ciclo reprodutivo, definida pelo aumento de volume da vulva com presença de corrimento sero-sanguinolento, e seu fim é determinado no momento em que a fêmea aceita a cópula com o macho. Nesse período, a fêmea aceita somente o cortejo do macho, sem aceitar a monta, sendo comum se observar a manutenção da cauda pressionada contra o períneo (OKENS, 2004). Destaca-se também o aumento do tamanho uterino, com secreções provenientes das glândulas endometriais (LÚCIO, 2018).

O corrimento vaginal sanguinolento observado no proestro ocorre em decorrência do aumento nas concentrações sanguíneas de estradiol folicular, que provoca diapedese eritrocitária, e ruptura de capilares subepiteliais vaginais (OLIVEIRA et al., 2003), sendo responsável ainda pelo edema na vulva, cornificação vaginal e sangramento uterino, tendo duração de aproximadamente nove dias, variando de três a 17, e aumento gradativo da aceitação ao macho (NELSON; COUTO, 2015).

O final do proestro propicia o aumento na amplitude do LH decorrente da resposta ovariana às gonadotropinas e crescente produção de estradiol. Assim, os folículos ovarianos se desenvolvem, amadurecem e secretam estradiol que é sintetizado pelas células dos folículos ovarianos (OLIVEIRA et al., 2003), até que atinja seu pico de aproximadamente $50 \mathrm{pg} / \mathrm{mL}$, um ou dois dias antes da onda de $\mathrm{LH}$, e declina antes do ínicio do estro (NELSON; COUTO, 2015), podendo levar de cinco a 20 dias para regredir completamente (OKENS, 1992).

Oliveira et al. (2003) relataram que o LH é liberado pela Adeno Hipófise sendo responsável pela maturação, ovulação e luteinização dos folículos ovarianos. Adicionalmente, a onda pré ovulatória de LH tem uma duração de 24 a 72 horas, sendo a mais longa observada na maioria das espécies estudadas. Decorrente do aumento do estradiol liberado nessa fase, ocorre proliferação e amadurecimento das células epiteliais da vagina, cuja estratificação pode ser avaliada pela citologia vaginal. Além disso, os leucócitos diminuem, propiciando o aumento de bactérias, principalmente as extracelulares (NELSON; COUTO, 2015).

Okens (2004) relatou que os níveis de Progesterona são basais durante o proestro, com excessão das últimas 12 a 48 horas, onde a progesterona se eleva em detrimento da queda dos níveis séricos de estradiol. Esse aumento nas concentrações séricas de progesterona provoca poliaquiúria, ou seja, aumento nos níveis de ferormônios (ALVES et al., 2002).

\section{Estro}

A fase do estro é incialmente detectada quando a cadela permite o coito firmando seus membros no chão e levantando a cauda, posição denominada de "bandeira", para que seja facilitada a penetração, com duração média de nove dias, variando de três a 21 (NELSON; COUTO, 2015; SILVA, 2016).

Nelson e Couto (2015) descreveram que, diferentemente da fase do proestro, a vulva fica menos túrgida e ocorre desde a diminuição até a ausência de corrimento sero-sanguinolento. Ocorre declínio na concentração de estradiol decorrente do processo final de maturação folicular, dias antes da ovulação, com aumento concomitante de progesterona e início da elevação sérica do LH (BONETTI et al., 
2004), sendo que a ovulação ocorre de 24 a 48 horas depois desse pico.

Essas alterações hormonais levam a mudanças comportamentais nas fêmeas, associadas ao estro e a onda pré ovulatória de LH, que promove a ovulação e a formação de corpo lúteo (NELSON; COUTO, 2015).Okens (2004) relatou que as células luteinizadas que produzem progesterona, são funcionais antes do desenvolvimento do corpo lúteo. Os oócitos primários ovulados permanecem nas tubas uterinas de dois a três dias para que possam amadurecer antes da fertilização. O tempo que os oócitos levam para maturar é designado pelo período fértil, e o sêmen do cão é capaz de fertilizar por três a quatro dias, podendo chegar a seis (NELSON; COUTO, 2015).

$\mathrm{Na}$ citologia vaginal percebe-se predominância de células superficiais, ausência de neutrófilos, além de uma matriz clara, leucócitos normalmente ausentes, e há presença de eritrócitos e bactérias (NELSON; COUTO, 2015).

\section{Diestro}

O Diestro tem duração de 60 a 90 dias, sendo marcado pelo período em que a fêmea não é mais receptiva ao macho, tornando-se refrataria à cobertura, diminuindo assim a atração do cão e diminuição da descarga vulvar, assim como diminuição de edema vulvar (SANTOS et al., 2017).

O diestro corresponde a fase lútea do ciclo estral. A concentração sérica de Progesterona aumenta, acima da concentração basal após as duas primeiras semanas da ovulação e da onda de LH, tornando-se dependente da quantidade de LH e prolactina, e entra em declínio pelos dois meses subsequentes e, nas cadelas gestantes, há uma queda drástica no pré-parto (NELSON; COUTO, 2015).

A progesterona é essencial para manutenção da gestação na cadela, e sua maior concentração sanguínea é detectável nessa fase do ciclo (CASTAGNO; MARTINS, 2017). A citologia vaginal demonstra uma redução abrupta no número de células epiteliais superficiais e reaparecimento de células intermediárias, neutrófilos e debris celulares, além de alguns linfócitos (BORDO et al., 2016). Endocrinologicamente, o diestro é encerrado quando os níveis de Progesterona assumem valores inferiores a $1 \mathrm{mg} / \mathrm{mL}$ (NELSON; COUTO, 2015).

\section{Anestro}

O anestro é marcado pelo fim da fase luteal e início de um novo proestro, com duração de aproximadamente 125 dias, onde ocorre a involução uterina nos próximos 120 dias da cadela que não gestou, e 140 dias na fêmea que gestou (OLIVEIRA et al., 2003; SOUZA, 2015) e reparação endometrial. Nessa fase a cadela não é receptiva e nem atrativa aos machos, não apresenta descarga vulvar e a vulva encontra-se pequena (SANTOS; LEAL, 2017). Dessa forma, o anestro é definido como uma fase de descanso sexual (NELSON; COUTO, 2015).

Clinicamente, não há diferenciação das fêmeas em diestro não gestante e em anestro, já que em ambas as fases, as cadelas apresentam inatividade sexual (OLIVEIRA et al., 2003). Oliveira et al. (2003) relataram que os ovários nessa fase apresentam baixa receptividade aos hormônios hipofisários, uma vez que os níveis presentes de Prolactina atuam como inibidor do eixo hipotalâmico-hipofisárioovariano.

Okens (2004) enalteceu que durante o anestro, os níveis de Estradiol e Progesterona encontram-se em níveis basais, com aumento do Estradiol no final desse estádio, além do aumento do LH. O endométrio descama 
nesse período, a atividade das glândulas endometriais e espessura do miométrio estão reduzidas. A citologia vaginal é quase acelular, com pouca quantidade de células parabais e células epiteliais intermediárias (NELSON; COUTO, 2015).

Okens (2004) relatou que é difícil identificar a causa do início de um novo ciclo reprodutivo, bem como há dificuldade em se delimitar a duração do anestro. Nelson e Couto (2015) relataram que é mais aplicável descrever o período interestral, que vai de um proestro a outro.

\section{ESTIMATIVA DO CICLO ESTRAL POR CITOLOGIA VAGINAL}

A citologia vaginal pode ser utilizada de maneira complementar, no manejo reprodutivo das fêmeas caninas para controle do ciclo estral por meio da utilização de swab estéril vaginal (VIEIRA et al., 2012), sendo um método não invasivo e que pode ser realizado com rapidez (CARDOSO, 2017). O controle estral está indicado em casos que se deseja induzir o estro, determinando o momento ideal para a cobertura ou inseminação artificial, bem como inibir sua ocorrência (OLIVEIRA; JUNIOR, 2006; SILVA, 2016).

A citologia vaginal demonstra a partir de uma análise subjetiva, a morfologia das células do epitélio vaginal, mediante a variação hormonal presente no decorrer do ciclo estral (KANCA et al, 2014; SOLANO-GALEGO; MASSERDOTTI, 2016).

Grandi e Vannucchi (2014), relataram que o método mais prático de coloração do material citológico é por meio do panótico rápico, composto por solução de triarilmetano, xantenos e tiazinas.

Conforti et al. (2014) descreveram que as modificações celulares visualizadas na citologia vaginal estão intimamente ligadas às alterações séricas hormonais durante cada fase do ciclo estral. Uma vez que o epitélio vaginal responde aos estímulos neuroendócrinos, ocorre maturação e diferenciação celular durante cada fase do ciclo, sendo as células do epitélio classificadas em basais, parabasais, intermediarias (pequenas, médias ou grandes) e superficiais (nucleadas ou anucleadas), como mostra a Figura 2 (CARDOSO, 2017).

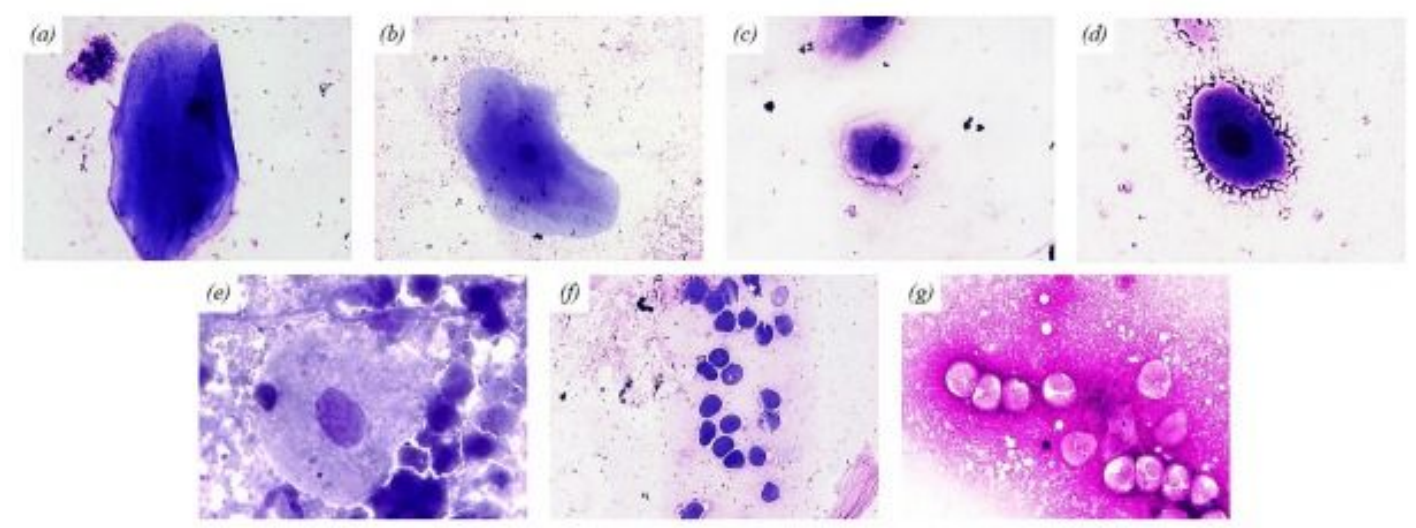

FIGURA 2: Células da citologia vagina. (a): célula superficial anucleada; (b): célula superficial nucleada; (c): células parabasal; (d): célula intermediária pequena; (e): célula intermediária grande; (f): eritrócito; (g): neutrófilo. Aproximação 600x. Fonte: CARDOSO (2017).

No proestro, pela ação do Estradiol, ocorre diapedese eritrocitária, onde a citologia vaginal é marcada por acentuada presença de células sanguíneas (VIEIRA et al., 2012), além de visualização de células epiteliais no esfregaço vaginal (SILVA, 2016). Cardoso (2017) relatou que $83,7 \%$ dos neutrófilos são observados na fase de 
proestro, além aumento de neutrófilos e eritrócitos, resultante da permeabilidade vascular.

A fase de estro provoca aumento nas concentrações séricas de Estradiol, alterando morfologicamente as células epiteliais vaginais, bem como a mucosa vaginal, provocando aumento de espessura nas camadas celulares em aproximadamente $80 \%$, quando comparado a fase de anestro, sendo as células superficiais queratinizadas (ALVES; COSTA, 2002; CARDOSO, 2014). Pode-se visualizar afastamento das células epiteliais decorrente da degeneração por morte celular associada a queratinização citoplasmática (COSTA et al., 2009).

No período de diestro é possível avaliar diversos grupos celulares, bem como acentuado número de neutrófilos, evidente após a fase folicular (SILVA, 2016; CARDOSO, 2017), uma vez que nessa fase não há estímulo para o macho e nem sinais relacionados a possíveis cruzamentos, podendo ser identificados alguns eritrócitos e bactérias (VIEIRA et al., 2012). Cardoso (2017) relata que a redução abrupta de células superficiais queratinizadas resulta no aparecimento de células intermediárias e parabasais.

Vieira et al. (2012) relataram que na fase de anestro se identifica células parabasais e intermediárias, com rara presença de neutrófilos e bactérias. A mucosa vaginal encontra-se fina, vermelha, com os vasos visíveis (SILVA, 2016). É válido salientar, que além do perfil citológico, dosagem de progesterona sérica e ultrassonografia também podem ser utilizadas para delimitar a fase do ciclo que as cadelas se encontram (CONFORTI et al., 2014).

\section{FISIOLOGIA DA OVULAÇÃO}

Nas cadelas, a produção de oócitos pelas células germinativas primordiais, ou oôgonias, e proliferação mitótica de células epiteliais durante a fase pré-natal até dois meses após o nascimento, é denominada oogênese (DERUSSI; LOPES, 2009). Serafim (2013) relatou que a migração das células germinativas primordiais, provenientes do saco vitelínico a crista gonadal, nas cadelas, ocorre por volta do $42^{\circ}$ dia após o coito.

As oogônias são células arredondadas, e de maior dimensão, que colonizam a crista gonadal, iniciando a gametogênese por meio de divisão mitótica. Na cadela, o início da meiose se dá após o período de quiescência mitótica das células germinativas (SERAFIM, 2013).

Os oócitos primários apresentam acentuada quantidade de mitocôndria, ocasionando aumento da atividade metabólica; aumento gradativo dos grânulos lipídicos com função ainda desconhecida, podendo ser uma fonte de reserva nutricional durante o desenvolvimento embrionário (SONGSASEN; WILDT, 2007).

Após as duas semanas seguintes ao nascimento, essas oogônias iniciam o processo de divisão celular, ingressando no Estádio I da meiose, ou de pré leptóteno, onde evoluem para oócitos primários. Sequencialmente, as células da pré granulosa circundam os oócitos, originando os folículos primordiais, e início da folículogênese (SERAFIM, 2013).

Só será retomada da divisão meiótica na puberdade, quando houver liberação de $\mathrm{FSH}$ e LH, que culminará na produção de oócitos secundários, que entrarão em estádio de repouso, em Metáfase II. Após a fertilização pelo espermatozoide do cão, a divisão celular será retomada finalizando a oogênese (ZERLOTINI, 2016). Assim, torna-se necessário um período de dois a três dias para finalização meiótica do 
oócito nas tubas uterinas, antes que a fertilização aconteça (SERAFIM, 2013).

A secreção de GnRH pelo Hipotálamo, promove secreção de FSH e LH pela Hipófise, que estimulam o desenvolvimento folicular, ovulação e formação de corpo lúteo. Em resposta as essas gonadotropinas, os ovários secretam Estradiol, Inibina e Progesterona. Uma vez iniciado, o desenvolvimento folicular levará a ovulação ou a atresia (THOMPSON, 2006).

Os fatores que desencadeiam o início do crescimento folicular não são bem compreendidos. No entanto, uma vez que se inicia o processo de foliculogênese com predomínio hormonal, o folículo só pode ovular ou sofrer atresia, caracterizada por morte folicular (SONGSASEN et al., 2017). Estabelecida a onda de crescimento folicular, diminui a reserva de folículos primordias quiescentes, sendo um estádio irreversível para a vida reprodutiva do animal (MONNIAUX, 2016).

Para a ovulação, é necessário que ocorra uma onda pré ovulatória de $\mathrm{LH}$, a fim de promover desenvolvimento final folicular até o estádio pré ovulatório. Estimase que $11 \%$ dos folículos tornam-se polioocitários na cadela, sendo muito superior a ocorrência nas outras fêmeas domésticas. Em gatas, por exemplo, estima-se que $3 \%$ dos folículos tornam-se polioocitários (DERUSSI; LOPES, 2009). Luvoni et al. (2005) relataram que a ocorrência de folículos polioocitários poderia se relacionar a alta densidade de folículos primordiais no córtex ovariano das fêmeas mais jovens, que acabam se algutinando.

Dessa forma, o período fértil na cadela é situado de dois a cinco dias após a ovulação, sendo entre o quarto e o sétimo após o pico de LH. Dessa forma, após a cobertura pelo macho, há um reservatório de espermatozoides viáveis nas tubas uterinas para que ocorra a fertilização (ALVES et al., 2002).

Após a ovulação, ocorre a fase luteal no ovário, marcada por intensa atividade proliferativa e vascular, que culmina em hipóxia e infiltração de células do sistema imunológico, provocando aumento contínuo de atividade esteroidogênica (PAPA et al., 2014).

A espécie canina, dentre as espécies domésticas, é a que apresenta maior intervalo do estro a fertilização, uma vez que essas fêmeas ovulam oócito(s) primário(s), e não secundário(s), como observado na maioria das fêmeas, necessitando de tempo adicional para se completar a fase de Meiose I, possibilitando que os mesmos sejam fertilizados pelo espermatozoide do cão (THOMPSON, 2006).

Com o uso de biotécnicas reprodutivas nas cadelas que visam a maturação e Fertilização In Vitro (FIV), as principais preocupações envolvem a qualidade dos e a quantidade de oócitos recuperados, visando a aparência do citoplasma, que deve ser homogêneo e com múltiplas camadas de Células do Cumulus (BINSFELD et al., 2014). No entanto, o uso dessas técnicas ainda possui muitas limitações, pois indíces de metáfase II é abaixo de $20 \%$, determinando baixa competência dos oócitos caninos, ou coleta em momento inoportuno do ciclo estral (PEREIRA et al., 2015).

\section{CONSIDERAÇÕES FINAIS}

O reconhecimento dos órgãos reprodutivos das fêmeas canis, bem como a maneira de interação fisiológica para controle de ciclo estral, é importante para que se possa realizar manejo reprodutivo eficiente, uma vez que se busca o nascimento de prole saudável sem comprometimento da saúde reprodutiva da cadela (FREITAS, 2017), bem como realizar o controle de superpopulações. Soma-se 
a isso o aumento de animais criados nos lares brasileiros, e o aumento da população de animais errantes, justificando a necessidade de se estabelecer critérios efetivos para a esterilização dessas fêmeas, que só será possível a partir do conhecimento anatômico e fisiológico do sistema reprodutor.

A possibilidade de se utilizar biotécnicas reprodutivas para aperfeiçoamento das raças que possuem alto valor zootécnico, como por exemplo o Dogo Argentino, bem para se eliminar defeitos genéticos que determinam afecções relacionadas a cada padrão racial, justificam estudos relacionados ao conhecimento da fisiologia reprodutiva de cadelas (EVANGELISTA et al., 2016).

Dentre as biotécnicas reprodutivas, a transferência de embriões em cadelas demonstra a falta de apelo socioeconômico, bem como as particularidades endócrinas e reprodutivas desses animais, que dificultam estabelecimento do tempo exato de utilização da técnica, além do número limitado de zigotos viáveis (APPARÍCIO; VICENTE, 2015).

A Inseminação Artificial em cadelas tem mostrado ser uma técnica efetiva, principalmente quando os progenitores são incapazes de realizar a cópula, tornando-se possível somente em decorrência do conhecimento anatômico e fisiológico do sistema reprodutivo da fêmea, mais precisamente do seu ciclo estral (KARLING et al., 2017).

Apesar de promissoras, pesquisas de biotécnicas reprodutivas em cães são ainda muito limitadas, principalmente pelo desconhecimento das particularidades reprodutivas envolvidas no ciclo estral das cadelas (BRUM et al, 2018).

As particularidades inerentes ao ciclo estral da cadela, associadas ao conhecimento das mesmas, propicia maior aproveitamento de cada ciclo estral, evitando tempo de espera desnecessário pelo próximo ciclo, além de permitir maior aproveitamento do estro natural.

O conhecimento das ações hormonais envolvidas no ciclo estral da cadela permite a indução da atividade reprodutiva através da manipulação farmacológica do ciclo estral, minimizando sempre os índices deletérios a espécie.

E por fim, mudanças na fisiologia desses animais provocam alterações reprodutivas que podem variar de leves a graves, culminando na maioria das vezes, na esterilização das fêmeas canis, e até comprometimento da vida do animal, decorrente do risco inerente ao procedimento cirúrgico.

\section{REFERÊNCIAS}

ALMEIDA, M. V. D.; RIAL, L. C.; LUSTOSA, J. P.; BICALHO, A. L. F.; ORTEGA, H. $H$. et al. Identificação imuno-histoquímica de VEGF e IGF-1 em ovários de cadelas em anestro e estro. Arquivo Brasileiro de Medicina Veterinária e Zootecnia, v. 67, n. 2, p. 334-342, 2015.

ALVES, I.; MATEUS, M.; LOPES DA COSTA, L. Monitorização do ciclo éstrico da cadela para inseminação artificial ou cruzamento. In: PROCEEDINGS OF THE VETERINARY SCIENCES CONGRESS, 2002, Portugal. Anais, Portugal, Oeiras, 2002. Disponível em: <http://horta.0catch.com/congressospcv/20.pdf/>.

APPARÍCIO, M.; VICENTE, W. R. R. Desenvolvimento embrionário e transferência de embriões em cadelas. Revista Brasileira de Reprodução Animal, v. 39, n. 1, p. 146-149, 2015. 
BARROS, P.M. Técnicas de Ovariosalpingohisterctomia (OSH) em cadelas: Revisão de literatura. 2010. Dissertação (Mestrado em Medicina Veterinária) Universidade Estadual Julio de Mesquita Filho, Jaboticabal - SP, 2010.

BEZERRA, M.B.; RONDINA, D.; LIMA, A. K.; OLIVEIRA, L. C.; CECCHI, R. et al. Quantitative and qualitative aspects of pre-natal foliculogenesis in caprine species. Ciência Rural, v. 8, p. 47-56, 1998.

BINSFELD, L. C.; DARRIBA, R. V.; BORGES, J. L.; OTUTUMI, L. K.; SANTOS, I. W. et al. Avaliação ovariana morfométrica e recuperação de complexos Cumulus oophorus de cadelas em diferentes fases do ciclo estral. Archives of Veterinary Science, v. 19, n. 2, p. 31-39, 2014.

BORDO, C.V.S; CORSI, L.G.T; SOUZA, A.K.; MARTINS, M.I.M. Características das células vaginais, endometriais e concentração de progesterona no ciclo estral de cadelas. Anais dos escontros anuais de iniciação cientifica da UEL. $26^{a}$ edição. 2016.

BRUM, D. S.; DELFINO, M.; SOUZA, P.; LEIVAS, F. G. Biotécnicas da reprodução uso de citologia vaginal esfoliativa para determinação de período fértil em cadelas . Anais de Ensino, Pesquisa e Extensão. Universidade Federal do Pampa, 2018.

BYSTED, B.V.; DIELEMAN, S.J.; HYTTEL, P.; GREVE, T. Embryonic developmental stages in relation to the LH peak in dogs. Journal of Reproduction and Ferility. Europa, v. 57, p. 181-186, 2001.

CARDOSO, C. F. R. Desenvolvimento folicular ao longo do ciclo éstrico na cadela e gata. Dissertação (Mestrado em Medicina Veterinária) - Universidade Lusófona de Humanidades e Tecnologia, Lisboa, 2017, 85 p.

CARDOSO, R. C. S. Terapêutica hormonal aplicada a reprodução da cadela . Acta Veterinária Brasilica. v. 8, p. 396-401, 2014.

CASTAGNO, K. L. B.; MARTINS, L. R. Insuficiência Luteal em cadela da raça American Bully - Relato de caso. Revista Brasileira de Reprodução Animal, Belo Horizonte, v. 41, n. 4, p. 723-726, 2017.

CONCEIÇÃO, M. E. B. A. M.; TEIXEIRA, P. P. M.; DIAS, L. G .G. G. Revisão de Literatura em Cirurgia de pequenos animais. Revista Investigação medicina veterinária. v. 15, n. 1, p. 10-15, 2016.

CONFORTI, V. A.; BRAVO, N. R. S.; FREITAS, G. L.; RODRIGUES, V. Detecção de estro em cadelas monitoradas por ultrassonografia e citologia vaginal utilizando as colorações de Papanicolau e panóptico rápido.; Enciclopédia Biosfera. Goiânia, v. 10, n. 19, p. 759-768, 2014.

COSTA, E.C.F.; LEGA, E.; NEVES, L. Estimativa da fase do ciclo estral por citologia vaginal em cadelas (Canis familiaris, LINNAEUS, 1758) da região de Ituverava-SP. Nucleus Animalium, [s.I.], v. 1, n. 2, p. 75-83, 2009. Fundacao 
Educational de Ituverava. Disponível em: <http://dx.doi.org/10.3738/1982.2278.310>.

DA SILVA, D. P. Canis familiaris: Aspectos da domesticação (Origem, Conceito, Hipóteses). Dissertação. Universidade de Brasília). Dissertação (Trabalho de Conclusão de Curso em Medicina Veterinária) - Universidade de Brasília, Brasília, 2011, 46 p.

DAVIDSON, A. P.; STABENFELDT, G. H. Reprodução e Lactação. In: Cunningham, J. G.; Klein. Tratado de Fisiologia Veterinária. 4 ed. Rio de Janeiro: Elsevier, 2008, cap. 469-494.

DERUSSI, A. A. P.; LOPES, M. D. Fisiologia da ovulação, da fertilização e do desenvolvimento embrionário inicial na cadela. Revista Brasileira de Reprodução Animal, v. 33, n. 4, p. 231-237, 2009.

DYCE, K. M.; SACK, W. D.; WENSING, C. J. G. A pelve e os órgãos reprodutivos de cães e gatos. In: DYCE, K. M.; SACK, W. D.; WENSING, C. J. G. Tratado de anatomia veterinária . 4 ed. Rio de Janeiro: Elsevier, 2010, cap. 15, p. 454-466.

EVANGELISTA, L. S. M.; FILHO, M. A. C. S.; SOUZA, J. A. T. Inseminação artificial em cadela da raça Dogo Argentino utilizando sêmen refrigerado: relato de caso. PUBVET, v. 10, n. 3, p. 244-247, 2016.

FREITAS, L. A. Avaliação ultrassonográfica bidimensional e doppler e perfil proteômico durante o ciclo reprodutivo de cadelas . Dissertação (Doutorado em Reprodução Animal) - Universidade Estadual do Ceará, Fortaleza, 2017, 113 p.

GOSSLER, V. S. A. Avaliação da proliferação celular e espessura do endométrio de cadelas em diferentes príodos do diestro . Dissertação (Mestrado em Fiopatologia animal) - Universidade do Oeste Paulista, Presidente Prudente, São Paulo, 2015.

GRANDI, F. VANNUCCHI, C. I. Aplicações da citologia vaginal na clínica médica de pequenos animais. In: BESERRA, H. E. O; COSTA, L. D. (Org). Citopatologia veterinária diagnóstica. São Paulo: MedVet, 2014, p. 99-119.

IBGE - Instituto Brasileiro de Geografia e Estatística Infográficos: dados gerais dos munícipios. 2015. Disponível em: <http://cod.ibge.gov.br/23230>.

JUNQUEIRA, L. C.; CARNEIRO, J. Aparelho Reprodutor feminino. In: JUNQUEIRA, L. C.; CARNEIRO, J. Histologia Básica. 12 ed. Rio de Janeiro: Guanabara Koogan, 2013, cap. 22, p. 427-446.

KANCA, H. K.; DALGIC, M. A.; SALAR, S.; IZGUR, H. Vaginal cytology after induction of ovulation in the queen: Comparison of postoestrus and dioestrus. Australian Veterinary Journal, v. 92, n. 3, p. 65-70, 2014.

KARLING, P. C., ROQUE, W. C.; OLISSON, D. C. Inseminação artificial a fresco em 
uma fêmea bulldogue inglês: relato de caso. Journal of Veterinary Science and Public Health, v. 5, n. 2, p. 194-210, 2017.

KÖNIG, H. E.; LIEBICH, H. G. Anatomia dos animais domésticos: texto e atlas colorido. Vol.2. Porto Alegre: Artmed, 2004, 400p.

KÖNIG, H. E.; LIEBICH, H.-G. Órgão genitais femininos. In: KÖNIG, H. E.; LIEBICH, H.-G . Anatomia dos Animais Domésticos. 4 ed. Porto Alegre: Artmed, 2011. cap. 11. p. 443-447.

LÚCIO, F. M. S. Apoptose folicular em cadelas e gatas ao longo do ciclo éstrico. 2018, 63 f. Dissertação (Mestrado em Medicina Veterinária) - Universidade Lusófona de Humanidades e Tecnologias, Lisboa, 2018.

LUCY, M.C.; SAVIO, J.D.; BADINGA L.; DE LA SOLTA, R.L. Factors that affect ovarian follicular dynamics in cattle. Journal of Animal Science, v. 70, p. 36153626, 1992.

LUNARDON, N. T.; SANTOS, K. C. S.; JUSTINO, R. C.; DESSUNTI, G. T.; SENEDA, M. M. et al. Population estimate of the preantral follicles and frequency of multioocyte follicles in prepubertal and adult bitches. Theriogenology, v. 83, n. 6, p. 1015-1020, 2015.

LUVONI, G. C.; CHIGIONI, S. ALLIEVI, E. MACIS, D. Factors involved in vivo and in vitro maturation of canine oocytes. Theriogenology, v. 64, p. 41-59, 2005. Disponível em: < 10.1016/j.theriogenology.2004.03.004>

MAZON, M. S.; MOURA, W. G. M. Cachorros e humanos: mercado de rações pet em perspectiva sociológica. Civitas - Revista de Ciências Sociais. Porto Alegre, v. 17, n.1, p. 138-158, 2017. Disponível em: <http://dx.doi.org/10.15448/19847289.2017.1.25292>.

MONNIAUX, D. Driving folliculogenesis by the oocyte-somatic cell dialog: Lessons from from genetic models. Theriogenology, v. 86, n. 1, p. 41-53, 2016.

NELSON, R. W; COUTO, C. G. Distúrbios do sistema reprodutor. In: Medicina interna de Pequenos Animais.Ed. Guanabara-Koogan, 3ª ed. 2011.

OKENS, A. C. S. Ciclo estral e manejo reprodutiv o da fêmea cadela In: ETTINGER, S. J.; FELDMAN, E. C. Tratado de medicina interna veterinária . 5 ed. Rio de Janeiro: Guanabara Koogan, 2004, cap. 157, p. 1592-1601.

OLIVEIRA, E. C. S.; MARQUES JÚNIOR, A. P. NEVES, M.M. Endocrinologia reprodutiva e controle da fertilidade da cadela - revisão. Archives of Veterinary Science, v. 8, n. 1, p. 1-12, 2003.

OLIVEIRA, E.C.S.; MARQUES JÚNIOR, A. P. Endocrinologia reprodutiva e controle da fertilidade da cadela. Revista Brasileira de Reprodução Animal. Belo Horizonte, v. 30, n. 1/2, p. 11-18, 2006. 
OLIVEIRA, W; PINTO NETO, A.; MOTA, M. F.; MARTINEZ, A. C.; FROZZA, B. C. Alterações em órgãos genitais de cães e gatos hígidos esterelizados cirurgicamente . Enciclopédia Biosfera, Goiânia, v. 15, n. 27, p. 33-41, 2018.

PAPA, P.; SOUZA, L. M.; SILVA, S. Glucose transporter 1 expression accompanhieshypoxia sesing in the cyclic canine corpus luteum. Reproduction, $v$. 147, p. 81-89, 2014.

PAYAN-CARREIRA, R.; PIRES, M.A. Multioocyte in domestic dogs: A survery of frequency of occurrence. Therio Journal, Portugal, v. 69, n. 8, p. 977-982, 2008.

PEREIRA, L. M. C.; BERSANO, P. R. O.; LIMA, A. F. M.; PANTOJA, J.C. F.; LOPES, $M$. D. Influência das fases de anestro e diestro na competência meiótica oocitária de cadelas. Brazilian Journal of Veterinary Research and Animal Science, v. 52, n. 3, p. 266-272, 2015. Disponível em: <DOI: 10.11606/issn.1678-4456.v52i3p266272>.

PREVIATO, P.F.G.P.; PINTO NETO, A.; WERNER, P.R., ACCO, A., MOTA, M.F. et al. Morphological alterations in the genital organs of cats and dogs from Rural Villages in the region of Umuarama-PR. Arquivo ciência veterinária e zoologia. Paraná, v. 8, n. 2, p.105-110, 2005.

REYNAUD, K.; FONTBONNE, A.; MARSELOO, N., CHEBROUT, M., VIARIS de LESEGNO, C. et al. In vivo meiotic resumption, fertilization and early embryonic development in the bitch. The Journal of the Society for Reproduction and Fertility. Reino Unido, v. 130, p. 193-201, 2005.

RIBEIRO, A. A. Dinâmica dos fatores angiogênicos em corpos lúteos de cadelas gestantes e pseudogestantes. 2018, 66 f. Dissertação (Pós-graduação em Biotecnologia animal do Curso de Medicina Veterinária) - Universidade Estadual Jílio de Mesquita filho, Botucatu, São Paulo, 2018.

RÔLO, J. L. J. Estudo da população e criopreservação de folículos ovarianos pré-antrais de cadelas . 2012, 70 f. Dissertação (Mestrado em Medicina Veterinária) - Universidade de Brasília, Distrito Federal, 2012.

SANTOS, N.D. LEAL, D. G. Aspectos fisiológicos da gestação em cadelas . In: Simpósio de trabalhos de conclusão de curso , v. 1, 2017, São Paulo. Simpósio.

SAPIN, C. F.; SILVA-MARIANO, L. C.; FIALHO-XAVIER, A. G.; TIMM, J. P. T.; PIOVESAN, A. D. et al. Patologias do sistema genital feminino de cães e gatos . Science and animal health. v. 5, n. 1, p. 35-56, 2017.

SCHNEIDER, M.; SANTOS, I. W.; GARCIA, L.; PESSOA, L. F.; MOREIRA, P. A. Z. et al. Alterações hematológicas e nas concentrações de glicose ocorridas nas diferentes fases do ciclo estral de cadelas. Revista científica de medicina veterinária , ano XIV, n. 29, 2017. 
SERAFIM, M. K. B. Definição de um meio de cultivo para o desenvolvimento in vitro de folículos pré -antrais caninos isolados . 2013. 142 f. Dissertação (PósGraduação em Ciências Veterinárias) - Universidade Estadual do Ceará, Fortaleza, 2013.

SHRESTHA, A.; SRICHANDAN, S.; MINHAS, V.; PANDA, A. K.; GRUPTA, S. K. Canine zona pellucida glycoprotein-3: Up-scaled production immunization strategy and its outcome of fertility. Vaccine, v. 33, n. 1, p. 133-140, 2015.

SILVA, L. D. M. Controle do ciclo estral em cadelas. Revista Brasileira de Reprodução Animal. Belo Horizonte, v. 40, n. 4, p. 180-187, 2016.

SILVA, M. E. M. Determinação das interleucinas IL6 E IL12 no endométrio ex vivo canino sob a influência de lipopolissacarídeos e hormônios esteróides. 2016, 43 f. Dissertação (Mestrado em Clínica Médica e Investigação Etiológica em Medicina Veterinária) - Universidade Federal de Uberlândia, Minas Gerais, 2016.

SOLANO-GALEGO, L.; MASSERDOTTI, C. Reproductive System. In: RASKIN, R. E.; MEYER, D. J. Canine and Feline Cytology: A color atlas and interpretation guide, 3 ed., Missouri: ELSEVIER, p. 233-236, 2016.

SONGSASEN, N., NAGASHIMA, J., THOGKITTDILOK, C. Endocrine and paracrine controls of canine follicular development and function. PUBMED, v. 2, p. 29-34, 2017. Disponível em: <doi: 10.1111/rda.12858>.

SOUZA, R. H. F. A. Avaliação sérica de estrógeno e progesterona por método de imunoensaio multianalito em cadelas durante o ciclo estral. 2015, $57 \mathrm{f}$. Dissertação (Mestrado em Reprodução Animal) - Universidade de São Paulo, São Paulo, 2015.

THOMPSON, F. N. Reprodução de Mamíferos do sexo feminino. In: REECE, W. O. Fisiologia dos animais domésticos . 12 ed. Rio de Janeiro: Guanabara Koogan, 2006. cap. 39, p. 644-669.

VIEIRA, M. M. F; OLIVEIRA, T. E. S.; OLIVEIRA, L. E. D.; DANTAS, W. M. F. Detecção do ciclo estral por meio de citologia vaginal de cadelas atendidas no Hospital veterinário da UNIVIÇOSA/FACISA. In: Anais IV SIMPAC, v. 4, n. 1, p. 143148, 2012. Minas Gerais: UNIVIÇOSA, 2012.

ZERLOTINI, M. F. Desenvolvimento folicular em fragmentos ovarianos de cadelas (Canis lupus familiaris) cultivados em meios "MEM" suplementado com soro de cadela no proestro e cadela gestante. 2016. 51 f. Dissertação (Mestrado em Medicina Veteriária) - Universidade Federal de Viçosa, Minas Gerais, 2016. 